\title{
UN DEBATE FILOSÓFICO ACERCA DE LOS GRUPOS ÉTNICOS TRADICIONALES EN AMÉRICA LATINA Y LA HISTORIA DE LA FILOSOFÍA
}

\author{
En memoria de Fernando Salmerón
}

urante los últimos años se ha desarrollado un importante debate filosófico en América Latina -al igual que en muchas otras partes del mundo- en relación con los problemas que plantea la multiculturalidad. Algunos de esos problemas se refieren a los derechos de las minorías étnicas, qué tipo de derechos son y cómo pueden fundamentarse desde un punto de vista moral, el carácter absoluto o relativo de principios y normas morales, la relación del Estado con los grupos étnicos minoritarios, la transición de un Estado homogéneo a un Estado plural, y las formas que podrían tomar las relaciones interculturales.

En este debate han participado tres de los más destacados filósofos latinoamericanos: Ernesto Garzón Valdés, Luis Villoro y Femando Salmerón (recientemente fallecido); el primero originario de Argentina y los otros dos de México. En el presente trabajo comento algunas de sus ideas sobre algunos de los problemas mencionados, analizando el papel que la historia de la filosofía juega en sus trabajos. Esto me permite presentar un resumen de las principales ideas y argumentos en el debate latinoamericano en torno a los problemas del multiculturalismo, al mismo tiempo que apoyar ciertas tesis acerca del papel de la historia de la filosofía para las discusiones filosóficas contemporáneas.

Para los propósitos de este trabajo, el término de «historia de la filosofía» se entiende como la discusión y asimilación crítica de ideas filosóficas originadas en el pasado, al menos en una generación anterior a la presente, y que han evolucionado en el tiempo. Esas ideas pueden estar asociadas al trabajo de algún filósofo en particular, pero pueden también tener un origen menos preciso.

Veremos que al enfrentar algunos de los problemas del multiculturalismo nuestros tres filósofos tratan con ideas filosóficas del pasado al menos en los tres siguientes sentidos: 
1) Como ideas que ellos incorporan de manera crítica a su propias tesis, por lo que esas ideas son útiles para dar forma a su pensamiento.

2) Como ideas que son características de alguna tradición filosófica, la cual constituye el trasfondo de apoyo para sus análisis. En breve explicaré el sentido en el que utilizo el término de «tradición filosófica».

3) Como ideas que son constitutivas del objeto mismo de análisis. Por ejemplo, el tipo de entidades sociales que están en el centro de la discusión que analizaremos son los grupos étnicos tradicionales y el Estado. Una de las tesis que aquí se presuponen es que la identidad del Estado, tanto como la de los grupos étnicos tradicionales, depende en cierta medida de las creencias que acerca de ellos tienen los miembros de las comunidades pertinentes. Por consiguiente, para entender la naturaleza y el papel del Estado es necesario analizar y comprender las concepciones acerca del mismo que prevalecen entre los agentes del propio Estado y entre los miembros de la sociedad civil. Pero el Estado evoluciona históricamente, tanto como lo hacen las ideas y las concepciones que son constitutivas de él. Por consiguiente, la plena comprensión del Estado y de esas ideas requiere del análisis de su origen y su evolución; y ese análisis es una tarea filosófica.

Si bien la tesis (1) no es problemática, (2) y (3) plantean cuestiones controvertibles. En lo que sigue ofrezco algunas razones a su favor, mediante la discusión de algunas de las ideas de nuestros tres filósofos que son representativas de sus concepciones y del debate. Comencemos por aclarar la noción de «tradición filosófica».

\section{Tradiciones}

Por «tradición filosófica» quiero decir algo más que una mera cadena de obras filosóficas y de ideas del pasado. Una tradición es un sistema conceptual dinámico, el cual tiene su origen en algún momento y perdura durante un periodo. Ese sistema está compuesto por tesis, conceptos y principios metodológicos.

Una tradición puede identificarse por medio de las ideas, conceptos y tesis que se reconocen como la piedra angular de la misma, las cuales en ocasiones (pero no siempre) están ligados al trabajo de alguna figura histórica, y son las que establecen estándares para el tratamiento de los problemas en cuatro aspectos: los problemas de fondo, los conceptos, los métodos y los fines.

Con respecto a los problemas de fondo, la tradición establece los tipos de problemas que se consideran legítimos. Por ejemplo, una cierta tradición en epistemología considera que los legítimos problemas filosóficos con respecto al conocimiento son los relacionados con la justificación, mientras que los problemas de la génesis del conocimiento y de su desarrollo, tanto 
desde la perspectiva individual como la colectiva, corresponde a las ciencias empíricas como la psicología y la sociología. En años recientes las epistemologías naturalizadas han desafiado a esta tradición.

Con respecto a conceptos, por ejemplo, una cierta tradición en filosofía moral, la cual podemos llamar «kantiana», tiene en la base de sus análisis conceptos como los de «racionalidad», «autonomía» y «dignidad». Diversos autores que siguen a esa tradición pueden diferir en la manera precisa en la que interpretan a esos conceptos y en la forma de concebir sus relaciones recíprocas. Pero siempre estarán basándose en los conceptos propuestos por Kant en primera instancia.

Con respecto a los métodos y los fines, por ejemplo, Garzón Valdés, Salmerón y Villoro se adhieren a una tradición que considera que una obra filosófica debe contener una elucidación de los conceptos a usar, debe desarrollar argumentos correctos, y debe ser útil para que la gente comprenda problemas de la vida cotidiana, tanto personales como sociales.

Conviene precisar que los conceptos y las tesis que de hecho usan y defienden los filósofos contemporáneos que continúan una cierta tradición, por lo general no son exactamente los mismos que usaron y defendieron los filósofos que se identifican como fundadores de la tradición en cuestión, o cultivadores anteriores de la misma. Pero suele aludirse a aquellas figuras históricas para dar puntos de referencia que permitan identificar a la tradición con la que está relacionada el trabajo del filósofo contemporáneo. ${ }^{1}$

Algunas obras realmente innovadoras no están relacionadas con tradición alguna. Por lo general ellas inauguran una tradición. Pero a veces lo hacen precisamente mediante un rompimiento explícito con alguna tradición establecida; por ejemplo, mediante una controversia con obras representativas de la tradición con la cual están rompiendo. De hecho el trabajo filosófico se beneficia ampliamente del diálogo y de la controversia, y las tradiciones muchas veces se desarrollan por medio de los debates. Pero hay y ha habido tradiciones cuya historia no depende del diálogo y de la controversia.

En suma, las tradiciones filosóficas se entienden aquí como sistemas conceptuales dinámicos. Una gran cantidad de obras filosóficas, si no es que la mayoría, tienen relaciones conceptuales con una o más tradiciones. Las tradiciones son históricas en el sentido de que tienen un origen y se desarrollan en el tiempo. Algunos filósofos pueden ser fieles a una sola tradición, la cual puede ser más o menos fácilmente identificable. Otros utilizarán conceptos, tesis y métodos de diferentes tradiciones. Muchos filósofos no necesariamente trabajan «dentro» o en relación con una única tradición.

\footnotetext{
${ }^{1}$ Esta idea de «tradición filosófica» está inspirada en la concepción de «tradición científica» que ha desarrollado Larry Laudan (véase Laudan 1996, pp. 146-147).
} 
Pero difícilmente se encontrará una obra filosófica seria que no esté conectada con al menos una tradición. La conexión puede consistir en que una o más tradiciones ofrecen el telón de fondo para los análisis de la obra en cuestión, o más raramente, en el sentido de que esa obra signifique una contribución sustancial a una nueva tradición.

\section{El papel de las tradiciones filosóficas en el debate acerca del multiculturalismo en América latina}

En sus trabajos acerca de los problemas del multiculturalismo Garzón Valdés, Salmerón y Villoro hacen reflexiones e incluyen referencias y análisis de ideas filosóficas del pasado. Los tres se refieren a ideas de filósofos clásicos en la tradición occidental, y también a ideas que en el pasado han defendido filósofos y pensadores de Latinoamérica y de otras partes del mundo. Muchas de esas ideas, aunque no siempre se reconozca su origen, se manejan en los debates públicos contemporáneos acerca de la naturaleza del Estado o acerca del reconocimiento de ciertos derechos, en los parlamentos, en los medios de comunicación y en general dentro de la esfera política.

Comencemos por analizar un trabajo reciente de Garzón Valdés (Garzón Valdés 1996). Lo veremos con detalle en virtud de que se trata de un artículo representativo de sus ideas sobre estos asuntos, y también porque él mismo resume en ese trabajo los principales puntos en debate.

\section{La tradición kantiana}

Garzón Valdés defiende de manera vigorosa algunas distinciones que de acuerdo con él muchas veces se pasan por alto al discutir el problema de los derechos de las culturas minoritarias. Eso ha dado lugar a confusiones muy serias, de las cuales él menciona cinco, aclarando los conceptos y las tesis en juego:

1. La confusión entre tolerancia y relativismo moral.

2. La confusión entre diversidad cultural y enriquecimiento moral.

3. La confusión entre génesis y desarrollo de la identidad personal y la necesidad de conservar y promover el desarrollo de la comunidad en la que se ha nacido.

4. La confusión entre unidad cultural y unidad institucional.

5. La confusión entre derechos jurídicos y derechos morales.

Garzón Valdés sostiene que estas cinco confusiones, que él llama «básicas», dan lugar a otras confusiones «derivadas», y todas ellas dan lugar a falsos dilemas. Pero los dilemas se disuelven tan pronto como queda claro que surgen de las confusiones básicas y de las derivadas (cf. Garzón Valdés 1996, p. 81). 
Con respecto al primer punto, Garzón Valdés sostiene que la tolerancia indiscriminada, la tolerancia pura sin ninguna restricción, termina por eliminar toda regulación sobre el comportamiento de los seres humanos. Por consiguiente es preciso distinguir entre la tolerancia sensata y la insensata, la «tolerancia boba». La diferencia entre ellas reside en las razones que se ofrezcan en favor de la tolerancia. La decisión entre la tolerancia sensata, la tolerancia boba y la intolerancia, debe hacerse sobre la base de la calidad de las razones que se den para ser tolerantes en situaciones específicas. Las buenas razones serán aquellas que presupongan un mínimo de objetividad, es decir, «la aceptación de criterios racionales para su defensa o condena» [de una acción particular o de un sistema de acciones] (Garzón Valdés, 1996, p. 83).

Aquí es donde Garzón Valdés proporciona su primera referencia histórica en ese trabajo, pues menciona a Sócrates para ilustrar el hecho de que hay límites que si se violan entonces la tolerancia se vuelve irracional: "Así lo pensó posiblemente Sócrates cuando, siendo presidente de la Asamblea de Atenas, se opuso al voto de la mayoría y se negó a condenar sin juicio individual previo a los diez generales que no habían recogido a los caídos en la batalla naval de las islas Arguinusas» (Garzón Valdés 1996, 82). Garzón cita a Sócrates diciendo: «Entonces yo fui el único de los pritanos que se opuso a que hicierais algo en contra de la ley, y voté en contra. Y aunque los oradores estaban dispuestos a denunciarme y hacerme arrestar sin más, consideré que debía arrostrar el peligro junto a la ley y lo justo antes de unirme a vosotros en decisiones injustas por temor de la prisión o de la muerte» (Platón, Apología de Sócrates, 32b; citado por Garzón Valdés 1996, 82).

Es evidente que el interés de esta cita no es de erudición histórica. Garzón Valdés podría haber usado cualquier otro ejemplo, o podría no haberse referido a otro filósofo para comunicar y apoyar su idea. Sin embargo, Garzón quería fortalecer su tesis de que la tolerancia sensata debe ir acompañada de un conjunto de prohibiciones, bajo pena de convertirse en tolerancia insensata. Para lograr ese efecto es que él cita a Platón, y se refiere a la figura y a la actitud moralmente intachable de Sócrates. Por medio de esa referencia Garzón nos recuerda un caso paradigmático de una acción digna de encomio realizada por una figura fundamental en la historia de occidente y en la historia de la filosofía. Al explotar la figura de Sócrates como paradigma de persona honesta, justa y sabia, la cita cumple una función pedagógica para explicar con claridad su tesis, pero más aún, la cita también juega el papel de una buena razón para convencer al lector a favor de la tesis de que es necesario establecer límites a la tolerancia. La razón que debería ser evaluada únicamente sobre la base de su peso como razón, se vuelve 
más persuasiva y es más fácil de comprender y de aceptar por medio de un ejemplo de esa naturaleza.

Pero la referencia a Sócrates cumple todavía una función más, a saber, la de reforzar la idea de que la tesis en cuestión es universal, es tan válida en Latinoamérica ahora como lo era en Grecia hace más de dos mil años. No olvidemos que el foco de la crítica de Garzón aquí es el relativismo moral. Por eso él insiste en la defensa de principios universales de racionalidad como fundamentos de una moralidad crítica de validez absoluta. Más aún, la referencia a Sócrates y a la obra de Platón en relación con la tolerancia significa apelar a la tradición que está detrás de toda la obra filosófica de Garzón Valdés. Él deja claro que su pensamiento se encuentra en línea con una tradición que comenzó hace veinticinco siglos y que, como veremos, alcanzó su madurez en el siglo XVIII con la obra de Kant, y que sigue vigorosa hasta nuestros días.

$\mathrm{Al}$ apelar a esa tradición Garzón Valdés consigue reforzar su punto de vista, dejando claro que lo que él está haciendo es enunciar de manera sistemática ciertas ideas que se han conocido y defendido durante muchos siglos. Nuevas propuestas, o viejas ideas reformuladas, deberán evaluarse contra el telón de fondo de esa tradición. Aquéllas que no encajen deberán ser excluidas. En buena medida ésta es una cuestión puramente lógica: las nuevas ideas, o viejas ideas reformuladas, sencillamente son compatibles con la tradición o no lo son. Pero no debe pensarse que una tradición es un esquema rígido en relación con el cual una idea nueva simplemente encaja, y es admitida, o no, y entonces es excluida. En ocasiones es posible modificar los elementos y la composición de una tradición para acomodar ideas que de otra manera serían excluidas. Aclararemos esta idea al examinar las contribuciones de Salmerón al debate, y al contrastar uno de sus puntos de vista con otro de Garzón Valdés. Por ahora pasemos a comentar otras referencias históricas en el artículo de Garzón.

Mientras que la mención de Sócrates reforzó su idea acerca de los límites de la tolerancia, Garzón Valdés ilustra el concepto de tolerancia sensata mencionando algunas de las razones aducidas por John Locke y por Bartolomé de las Casas en defensa de la tolerancia religiosa.

Pero la tradición dentro de la cual trabaja Garzón exige razones. Por eso la siguiente referencia histórica aparece en el contexto de la explicación de las condiciones que deben satisfacerse para considerar a ciertas razones como buenas razones a favor de la tolerancia. De acuerdo con él, «las buenas razones son las que parten de una actitud de imparcialidad, es decir, de la consideración de los intereses de los demás en tanto seres autónomos, capaces de formular planes de vida respetables en la medida en que no violen el principio de daño sostenido por John Stuart Mill o no sean expresiones 
de una incompetencia básica que dé lugar a formas de paternalismo éticamente justificable» (Garzón Valdés 1996, 84). Nuevamente, la referencia histórica no era necesaria para su argumento, pero sirve para reforzar su tesis y mostrar la tradición respetable que está detrás de la idea.

En línea con esa tradición, Garzón Valdés deja claro que la tolerancia sensata no tiene nada que ver con el relativismo moral. Según él, sólo la tolerancia boba aceptaría al relativismo moral como su fundamento. Pero es un error muy serio el pensar que se puede ser tolerante sólo sobre la base del relativismo moral. Quienes cometen este error, pero aceptan al mismo tiempo la idea correcta de que la tolerancia es característica de las sociedades democráticas, enfrentan un falso dilema. Pues piensan que o bien deberían ser tolerantes, en cuyo caso no podrían articular una defensa objetiva de la democracia, o bien deberían defender la democracia de manera racional, pero entonces no podrían ser tolerantes (Garzón Valdés 1996, p. 84). Se trata aquí de una confusión derivada de las confusiones básicas de las que habla Garzón.

Todavía otro falso dilema que surge de la confusión entre tolerancia y relativismo moral (cuando se considera que éste último es una consecuencia necesaria de la diversidad cultural), es el que establece que o bien uno es tolerante, en cuyo caso no sería posible defender la universalidad de los derechos humanos, o bien uno defiende tal universalidad, pero entonces se convierte en un etnocentrista intolerante.

La concepción del «aislacionismo moral» de las diferentes culturas, de acuerdo con Garzón Valdés, «postula el abandono de toda perspectiva prescriptivamente universal en la moral y la limitación a la descripción de hábitos y costumbres de cada pueblo, para de ahí inferir lo que debe ser moralmente en esa sociedad» (Garzón Valdés 1996, 85). Pero para Garzón aquí subyace una falacia de tipo naturalista. De la mera existencia de diversas culturas no es posible inferir sin más que todas las normas que de hecho existen en ellas deban ser respetadas; ni siquiera puede inferirse que la diversidad cultural per se sea algo valioso: «La historia abunda en ejemplos de formas colectivas de vida respecto a las cuales cuesta encontrar argumentos morales que permitan concluir la necesidad de su conservación o promoción.» (Idem.).

Aquí entra otra referencia histórica, ahora para mostrar que el falso dilema entre vigencia universal de los derechos humanos y etnocentrismo tiene «antecedentes venerables». Garzón cita a Michele de Montaigne: «[...] no tenemos otro patrón de la verdad y la razón que los ejemplos e ideas de las opiniones y costumbres que diariamente oímos y vemos en el país donde vivimos. Allí está siempre la religión perfecta, la mejor Constitución, el más racional y supremamente noble uso de todas las cosas» (Michel de 
Montaigne, Oeuvres Complètes, I:31, Paris, Gallimard, 1962, p. 203). Con esto Garzón deja claro que no está criticando una confusión novedosa.

Con respecto al dilema de ser tolerante pero relativista, o defender la universalidad de los derechos humanos pero al costo de ser etnocentrista, el movimiento que hace Garzón Valdés es el de argüir que quienes creen que se trata de un legítimo dilema pasan por alto el hecho de que existe una base ética mínima que hace posible la coexistencia de las diversas culturas desde un punto de vista moral. Esa base ética mínima se encuentra en el origen de la idea moderna de derechos humanos. La idea es que «todo ser humano racional tiene que aceptar dos proposiciones centrales: el derecho a la autodefensa y la prohibición de dañar arbitraria o innecesariamente a sus semejantes» (Garzón Valdés 1996, p. 86). Ninguna persona racional podría rechazar estos dos principios, ni ninguna sociedad podría rechazarlos racionalmente, bajo pena de desaparecer más bien pronto.

Por medio de esta discusión llegamos al meollo de la posición de Garzón Valdés, pues ahí él recurre a los conceptos de autonomía y de racionalidad. Esto queda claro al discutir las siguientes confusiones. Con respecto a la segunda, la confusión entre diversidad cultural y enriquecimiento moral, Garzón sostiene que surge cuando se pasa por alto la diferencia entre moral positiva y moral crítica. La moral positiva está constituida por los valores y principios de hecho aceptados en una sociedad determinada. La moral crítica está constituida por principios que serían aceptables por cualquier persona racional, independientemente del contexto en el que se esté desenvolviendo (universabilidad), siempre y cuando examine esos principios de manera racional e imparcial.

La tercera confusión es aquélla entre génesis y desarrollo de la identidad personal y la necesidad de conservar y promover el desarrollo de la comunidad en la que se ha nacido. Aquí Garzón menciona explícitamente una idea de Johann Gottfried von Herder, la cual fue introducida en el debate por Fernando Salmerón (cf. Salmerón 1996, 72.) La idea es la de considerar como una necesidad humana básica la de pertenecer a un grupo dentro del cual hay una comunidad de lengua, de territorio, de memoria y donde hay un proyecto común. Herder postuló que esta necesidad es tan básica como la de alimento o la de abrigo. Salmerón trajo esta idea al debate con aprobación, pero Garzón Valdés la ha rechazado por completo. Analizaré las diferencias entre los dos autores sobre esto más adelante, al revisar las contribuciones de Salmerón. Por ahora pasemos a discutir las dos últimas confusiones que analiza Garzón. La cuarta confusión consiste en la creencia en que hay una relación intrínseca entre unidad cultural y unidad institucional, lo cual supone la idea de que las entidades colectivas pueden ser sujetos morales. 
Garzón Valdés desecha esta confusión arguyendo que esa última idea es simplemente incorrecta.

Garzón menciona leyes nacionales e internacionales que han establecido excepciones sobre la base de membresías a diferentes grupos (cf. Garzón Valdés 1996, 98-99). Por ejemplo, el artículo 27 del Pacto Internacional sobre Derechos Civiles y Políticos, aprobado por las Naciones Unidas el 19 de diciembre de 1966, estableció que en los Estados donde hay minorías étnicas, lingüísticas o religiosas, las personas pertenecientes a esas minorías no podrían ser privadas de su derecho, en común con otros miembros del grupo, a tener su propia vida cultural, a profesar y practicar su propia religión y a emplear su propio idioma (Garzón Valdés, 98). En parte sobre la base de esta disposición se han establecido un buen número de leyes a nivel nacional e internacional que entran en conflicto con ordenamientos superiores.

El problema que Garzón ve en estas disposiciones de excepciones a las leyes es que se basan en la idea de que los grupos, digamos étnicos, tienen derechos morales, y no sólo cierto status jurídico. Pero esto significa, de acuerdo con él, otorgar prioridad a los derechos de grupo frente a los derechos de los individuos (cf. p. 100). La idea que se arguye con frecuencia a favor de esa posición es que hay derechos culturales que requieren una protección institucional, pues las estructuras culturales ofrecen el contexto de elección para los individuos (como lo ha sostenido Kymlicka 1989, 178).

Garzón rechaza esa idea porque supone que hay un «derecho natural» de las culturas a su perpetuación. Y objeta tal idea citando con aprobación a Chandran Kukathas: «los grupos o comunidades no tienen una primacía moral especial en virtud de alguna prioridad natural. Son formaciones históricas mutables -asociaciones de individuos- cuyas pretensiones están abiertas a la evaluación ética. Y toda evaluación ética tiene, en última instancia, que considerar cómo los individuos reales han sido, o pueden ser afectados, y no los intereses del grupo en abstracto» (cf. Garzón Valdés 1996, 103; Kukathas, «Are there any cultural rights?», en Kymlicka 1995, 234).

La quinta confusión es aquélla entre derechos jurídicos y derechos morales. Garzón no encuentra nada objetable en el reconocimiento de derechos colectivos, como se hace por ejemplo en el Proyecto de Declaración de los Derechos de los Pueblos Indígenas de las Naciones Unidas, al hablar de los derechos de los pueblos indígenas «de existir en la paz y la seguridad como pueblos distintos y ser protegidos contra el genocidio...» (Garzón Valdés, 1996, 104). Pero no debería olvidarse que los derechos en cuestión son derechos jurídicos, no morales. 
El problema para Garzón es que en ocasiones hay formulaciones en donde se insinúa la confusión entre ambos tipos de derechos. Como ilustración Garzón ofrece una cita de Luis Villoro en donde defiende la idea de que los derechos colectivos son «condición» de los derechos humanos individuales. Esto sugiere que se está considerando que las entidades colectivas son sujetos morales, idea que como vimos Garzón rechaza por completo. Los derechos morales sólo pueden pertenecer a individuos, y uno no debería dejarse confundir por el hecho de que los derechos jurídicos deben estar fundamentados sobre derechos morales (Garzón Valdés 1996, 104). La cita que ofrece Garzón es de un artículo periodístico de Villoro en el diario mexicano La Jornada (Ciudad de México, 26 de septiembre de 1995). Una afirmación semejante se encuentra en Villoro 1995. Sin embargo, en subsecuentes discusiones inéditas Villoro ha dejado claro que su posición es la de atribuir derechos morales únicamente a individuos, y que en todo caso está por demostrarse la manera de fundamentar la existencia de derechos morales de entidades colectivas.

Garzón Valdés piensa que el supuesto de que existen derechos morales colectivos implica la postulación de entidades no individuales como agentes morales, y ésa es una concepción antropomórfica de las sociedades que es incorrecta. Además, concluye Garzón, ese supuesto multiplica las entidades del modo que tanto irritaba a Guillermo de Occam (Garzón Valdés 1996, 106).

Ésta es la última referencia a un pensador clásico en el artículo bajo análisis. Sin embargo, cuando Garzón Valdés propone su idea positiva, a saber, que lo que urge en América Latina es que se apliquen de manera efectiva las leyes vigentes, pues la mayor parte de ellas están basadas sobre principios morales aceptables, sostiene que «[b]uena parte de la injusticia que signa nuestro continente es el resultado de una secular ineficiencia de las leyes o de su aplicación en directa contradicción con el marco constitucional» (Garzón Valdés 1996, 107). Ésta es una afirmación histórica, por medio de la cual sugiere una explicación, aunque tal vez parcial, de la desastrosa situación en la que han vivido las minorías indígenas en Latinoamérica. En este punto, Garzón de nuevo ofrece dos citas de personajes históricos, pero en esta ocasión no para identificar y apoyarse en su tradición filosófica, sino para reforzar la tesis de que gran parte de los problemas de las minorías étnicas en América Latina provienen de la proclividad de las autoridades estatales a actuar al margen de la ley. La primera cita es del peruano Manuel González Prada, quien noventa años antes de que Garzón escribiera este artículo había afirmado: «Hay un hecho revelador: reina mayor bienestar en las comarcas más distantes de las grandes haciendas, se disfruta de más orden y tranquilidad en los pueblos menos frecuentados por las autoridades» 
(Manuel González Prada, Nuestros Indios, en Páginas Libres, Horas de Lucha, Caracas, Biblioteca Ayacucho, 1976, 343). Pero dos siglos y medio antes, lo mismo había sido ya reconocido por el Marqués de Mancera, Virrey del Perú, quien en 1648 había escrito: «en fe de la distancia se trampea la obediencia» (cf. Garzón Valdés 1996, 107).

Estas dos citas históricas cumplen dentro de la explicación sociológico-política-histórica que Garzón ofrece un papel análogo al de las citas histórico-filosóficas en relación con sus ideas filosóficas. En el presente caso, Garzón cita a testigos del hecho que él está enunciando. Esos testigos ofrecen evidencia de la existencia del hecho al que él se refiere, incluso en el siglo XVII. Su testimonio sirve de apoyo a Garzón para convencer al lector, pero más aún, la evidencia que presentan sirve como razón a favor de su tesis. De modo análogo las referencias a ideas dentro de su tradición filosófica sirvieron no sólo para mostrar que tenían antecedentes venerables, sino que se constituyeron en razones a favor de sus tesis. El hecho de estar articuladas dentro de una tradición les dio mayor fuerza.

En suma, hemos visto que aunque el argumento de Garzón Valdés no es histórico, él utiliza algunas referencias históricas. Y si bien éstas son escasas, están insertadas en momentos apropiados y desempeñan el papel de dejar claro que hay una venerable tradición en relación con la cual el autor desarrolla sus ideas. Además de cumplir una función pedagógica al ayudar al autor a presentar sus ideas de manera comprensible, las referencias también desempeñan un papel retórico para persuadir al lector. Pero sobre todo, esas referencias cumplen la función racional de constituir razones para las tesis que el autor defiende.

Así pues, el artículo de Garzón Valdés que hemos examinado muestra que aun si una obra trata de análisis puramente conceptuales relacionados con problemas contemporáneos puede haber, y por lo general hay, conexiones entre las ideas del autor y una o más tradiciones dentro del pensamiento filosófico occidental. Tal conexión puede ser explícita, como Garzón lo ha hecho en buena medida, o puede permanecer implícita. Pero incluso si la conexión no es explícita, queda establecida por medio de la red de conceptos a los cuales recurre la obra, los métodos que utiliza y las tesis de fondo que defiende.

Señalemos, finalmente, que una obra particular puede tener una o varias de las siguientes consecuencias con respecto a la tradición con la que esté relacionada:

1) Puede enriquecer la tradición proponiendo nuevas aplicaciones de la misma (ya sea a problemas nuevos, o a problemas antiguos pero vistos desde perspectivas novedosas). 
2) Puede modificar la tradición, por ejemplo mediante la incorporación de nuevos elementos, a nivel sustancial o a nivel metodológico.

3) Puede criticar la tradición, e incluso llegar a romper con ella.

\section{Herder y Kant}

Este tipo de consecuencias con respecto a las tradiciones se apreciara más claramente al analizar algunas de las contribuciones de Fernando Salmerón. Para ello comentaremos el artículo «Ética y diversidad cultural» que escribió para el volumen 12, Cuestiones Morales, de la ENCICLOPEDIA IBEROAMERICANA DE FILOSOFÍA (Salmerón 1996. Reproducido en Salmerón 1998). La cuestión principal que discute Salmerón es el llamado «derecho a la diferencia» o «la política del reconocimiento», y la analiza básicamente como un problema moral, pues es el que está en la base de propuestas de solución a los niveles jurídico y político.

Salmerón sostiene que en última instancia la política del reconocimiento debe estar basada en el concepto de la persona como agente moral. Pero hace hincapié en que el tratamiento del problema requiere una serie de conceptos que están estrechamente ligados entre sí: «dignidad», «identidad» y «autonomía».

Salmerón nos recuerda que el concepto de dignidad está en la base de la política de la igualdad, mientras que el concepto de identidad es el que fundamenta la política del reconocimiento, puesto que son las identidades individuales y colectivas las que luchan por el reconocimiento. Las identidades específicas se afirman sobre la base de diferencias que caracterizan a los miembros del grupo y que los distinguen de otros ciudadanos. Pero Salmerón insiste en que el concepto de dignidad debe estar también en la base del reconocimiento de los derechos colectivos de los grupos étnicos tradicionales. La condición para el reconocimiento de las diferencias y de las identidades y derechos colectivos es el respeto y la preservación de la dignidad personal. Al desarrollar su argumento Salmerón se apoya en ideas de filósofos contemporáneos así como de filósofos del pasado. Examinemos algunos de sus movimientos claves con el fin de analizar el papel de sus comentarios históricos.

Salmerón tiene el interés de señalar que muchos de los conceptos necesarios para la discusión actual tienen una larga historia, muchos de ellos habiendo sido configurados desde la obra de pensadores renacentistas (Salmerón 1996, 74). En particular, Salmerón subraya que en la filosofía moderna ha habido un entrelazamiento de dos ideas que son centrales para el problema del multiculturalismo: la idea de Herder ya aludida de que es una necesidad humana la de pertenecer a una comunidad, «que ofrece al individuo seguridad, bienestar y condiciones de realización personal, y, por encima 
de ella, el ideal humanista de universalidad y tolerancia» (Salmerón 1996, 72-73). Pero Salmerón deja claro que los conceptos y sus relaciones no han permanecido estáticos; por el contrario, han evolucionado. Y aunque Salmerón no lo dice explícitamente, su propio trabajo es una contribución al desarrollo y a la articulación de la red de conceptos que se requiere para tratar adecuadamente los problemas del multiculturalismo.

Una de las principales propuestas de Salmerón es la de incorporar la idea de Herder antes mencionada dentro de la tradición kantiana en la cual desarrolló su trabajo. Esto plantea un problema interesante, pues Garzón Valdés también ha desarrollado su trabajo en relación con esa tradición, pero mencionamos ya que él rechazó la idea de Herder. Así pues, ambos autores defendieron sobre esta cuestión puntos de vista encontrados, pero bajo la perspectiva de la misma tradición. ${ }^{2}$ ¿Significa esto que al menos uno de ellos cometió algún error lógico? Creo que la respuesta debe ser definitivamente negativa. De hecho, aquí encontramos la situación aludida antes en la que la incorporación o la exclusión de una idea dentro de una tradición no es una cuestión únicamente de compatibilidad lógica entre la idea en cuestión y las ideas ya establecidas dentro de la tradición, como si éstas formaran un conjunto rígido e inmutable de ideas. Un autor que quiere incorporar una idea dentro del contexto de una tradición establecida puede reorganizar y ampliar la tradición de manera que encaje la nueva idea sin dar lugar a un sistema conceptual incoherente. Pero esto puede implicar la modificación o incluso la eliminación de viejas ideas. Ésta es la línea que Salmerón siguió.

La diferencia de opinión entre Garzón Valdés y Salmerón (y también con Villoro, como veremos), alcanza al concepto de identidad personal. Garzón Valdés distingue correctamente entre identidad personal e identidad social, y hace hincapié en que no deben confundirse. Sobre la base de esta distinción sugiere que tiene sentido hablar de una «identidad cosmopolita» o, recurriendo de nuevo a Kant, hablar de «ciudadanos del mundo». $\mathrm{Su}$ conclusión es que no hay ninguna razón para pensar que un «ciudadano del mundo»o un individuo cosmopolita tiene una identidad menos desarrollada que la de personas que han crecido dentro de una cierta cultura local con la cual se identifican.

Debemos dejar claro que ni Salmerón ni Villoro defienden la idea de que la identidad personal sea lo mismo que la llamada identidad social. Tampoco

\footnotetext{
${ }^{2}$ Sobre la filiación kantiana de Garzón Valdés véase la «Introducción» de Manuel Atienza a Garzón Valdés 1993. Para una breve pero muy lúcida discusión de la teoría moral de Salmerón, véase Isabel Cabrera 1996, en donde además del artículo que estarnos analizando alude a otros trabajos, entre ellos Salmerón 1971, 1998 y 1991.
} 
defendería ninguno de los dos la idea de que cualquier cultura debe ser respetada a cualquier precio. Más aún, Salmerón fue explícito al rechazar la idea de que la identidad personal puede reducirse al papel social del individuo en una cierta comunidad haciendo caso omiso de la autonomía del individuo para la acción moral (Salmerón 1996, 83). Sobre esto no hay discusión entre Garzón Valdés y Salmerón. Sin embargo, la diferencia reside en que Garzón Valdés rechaza la posibilidad de extender el concepto de dignidad a entidades colectivas, y también excluye la idea de considerar seriamente que hay una importante contribución del medio social a la identidad personal, con consecuencias morales.

Al proponer que estas ideas pueden incorporarse al marco conceptual kantiano, Salmerón no deja lugar a dudas de que los derechos fundamentales son derechos individuales (Salmerón 1996, 79). Más aún, los derechos morales individuales fundamentales establecen los límites que no pueden ser traspasados en nombre de los derechos del grupo. Éste es el principio negativo establecido por Kant: el principio de la humanidad como un fin en sí mismo. Pero Salmerón sugiere la posibilidad de tratar a las entidades colectivas de manera análoga, siempre y cuando no se olvide que las entidades colectivas no son sujetos de conciencia en el mismo sentido en que lo son las personas. Las entidades colectivas son construcciones a partir de sus miembros individuales, son «representaciones intersubjetivas al servicio de un proyecto común» (Salmerón 1996, p. 77).

Manteniendo este supuesto, Salmerón reconoce que las personas son parcialmente construcciones sociales: «Mi propia identidad como persona... viene a ser el resultado parcial de una negociación con los demás miembros de las comunidades en que participo, y de la manera en que me apropio de sus ideales y creencias, de sus normas y gustos. Hasta el punto que bien pueda ser que la realización misma de un ideal de perfección y de vida buena se haga posible y se acreciente en esa participación y dentro de esa comunidad. Y que el desarrollo de mi identidad dependa del reconocimiento de los otros y gane su lugar en el intercambio» (Salmerón 1996, p. 76).

Esta idea puede aplicarse a individuos y a comunidades y tiene consecuencias mayores desde un punto de vista moral: «Porque lo mismo en las personas que en los grupos, un reconocimiento humillante o simplemente inferior puede contribuir a deformar la imagen que una persona o una colectividad tienen de sí mismas» (idem.).

De esto no se sigue que toda cultura merezca respeto por el mero hecho de existir. Por el contrario, lo que claramente se sigue es que ninguna cultura que traspase el umbral de la dignidad humana debe ser respetada, moralmente hablando. En esto coinciden plenamente Salmerón y Garzón Valdés. 
La tesis de Salmerón no implica negar la posibilidad, y en algunos casos la deseabilidad, de que haya personas cosmopolitas o ciudadanos del mundo. Él, tanto como Villoro, aceptaría esto sin reparo alguno. Ambos reconocerían en Garzón Valdés un claro ejemplo de una persona cosmopolita. Garzón nació en la Argentina y, como él mismo dice, por razones de biografía política ha vivido en Alemania por mucho tiempo. Sin embargo, ha viajado intensamente y ha enseñado en muchos países, sin perder jamás su compromiso y su amor por América Latina.

Pero vale la pena hacer notar que la existencia de individuos cosmopolitas no contradice la idea de que las identidades personales son constituidas al menos parcialmente por las comunidades en las cuales la persona creció. Tampoco contradice la idea de que son las comunidades las que ofrecen el trasfondo de elecciones de planes de vida y de concepciones de la vida buena, y que por lo tanto en ambos sentidos las comunidades son necesarias para los individuos. La posibilidad de individuos cosmopolitas es compatible con la propuesta de Salmerón de incorporar la idea de Herder dentro de la concepción kantiana. Simplemente habrá que tomar en cuenta que hay individuos cuyas necesidades pueden ser, y quizá deban ser, satisfechas por diversas comunidades.

Al proponer este modelo, fiel a la tradición kantiana, Salmerón no sólo hace una contribución positiva al debate, sino que al mismo tiempo articula una crítica a ciertos puntos de vista. En particular, Salmerón se opone en este aspecto al modelo defendido por Charles Taylor en su artículo «Multiculturalism» (Taylor 1994). Salmerón muestra que Taylor dejó de ver un punto importante de la ética kantiana. Pero la discusión no tiene sólo un interés de erudición histórica. Lo que está en juego es la posibilidad de construir ahora modelos que sean adecuados para abordar los problemas de las sociedades contemporáneas multiculturales.

En efecto, de acuerdo con Salmerón, Taylor rechaza la perspectiva kantiana porque pasó por alto una fina distinción que se encuentra en La Fundamentación de la Metafísica de las Costumbres. Se trata de la distinción entre dos posibles principios de la moralidad, de acuerdo con la cual se oponen «dos fines de la vida de signo positivo, que pueden ponerse en relación con nuestros deberes: "la propia perfección", y "la felicidad ajena"» (Salmerón 1996, 81).

Es posible proyectar estos dos principios a la esfera pública, pero entonces el ideal de perfección sólo puede pensarse en términos negativos. La propia perfección sólo puede ser un asunto propio, individual y privado. Las comunidades sólo pueden mantener espacios abiertos para la realización de los planes de vida, preservando la dignidad y la autonomía. «Por contraste, el deber de justicia, que consiste en contribuir a la felicidad ajena, es un deber 
perfecto que nos compete a todos y, más que a nadie, a nuestras organizaciones y poderes» (idem.) Éste es el movimiento clave mediante el cual Salmerón fundamenta dentro de la tradición kantiana el derecho de los individuos a pertenecer a una comunidad, así como las obligaciones de la comunidad frente al individuo.

Al mismo tiempo Salmerón subraya que el concepto de dignidad sólo puede concebirse como un fin negativo: establece los límites que nadie puede traspasar, y por consiguiente esos límites son inamovibles incluso frente a derechos del grupo.

Taylor no contempla la posibilidad de incorporar la idea de la necesidad de pertenencia a una comunidad como una necesidad humana básica. Más aún, de acuerdo con Salmerón, de manera equivocada atribuye el origen del punto de vista liberal conservador de que el Estado y las comunidades deberían permanecer neutrales con respecto a las elecciones de los individuos a las ideas de Kant acerca de la dignidad. Y por eso es que Taylor rechazó el modelo kantiano. Pero Taylor no vio ni la fina distinción a la que alude Salmerón, mencionada arriba, ni la concepción de la dignidad como un fin negativo. Si Taylor se hubiera dado cuenta de esto, alega Salmerón, no sólo hubiera tenido que aceptar el modelo kantiano, sino que hubiera visto que la idea de Herder es compatible con el esquema de Kant y hubiera contado con el poderoso aparato conceptual kantiano para fundamentar su teoría moral del multiculturalismo.

De esta manera, Salmerón propone un modelo según el cual es posible extender el concepto de dignidad a las comunidades, y es posible reconocer derechos de las comunidades como algo más que sólo derechos jurídicos, pero sin incurrir en las confusiones que Garzón Valdés comentó. La posición de Salmerón al mismo tiempo preserva intacta la esfera de la dignidad personal.

Como ya sugerí, aunque esta discusión es de interés para la erudición kantiana, en el contexto del artículo de Salmerón y en relación con los debates actuales sobre el multiculturalismo, tiene un significado mucho más amplio. La elucidación y la articulación de conceptos originalmente forjados en el pasado, en el artículo de Salmerón sirven para los siguientes propósitos:

1) Inspiran las propias ideas de Salmerón y le confieren respetabilidad.

2) Más importante, con ellos Salmerón construye un modelo que él considera el mejor para abordar los problemas morales del multiculturalismo.

3) Ese mismo modelo, basado en análisis históricos, es usado para articular una crítica a otro influyente punto de vista contemporáneo (el de Taylor). 


\section{Marcos conceptuales}

Ahora examinaré la tesis de que los marcos conceptuales y las tradiciones son fundamentales para el análisis de los problemas del multiculturalismo, puesto que uno de esos problemas centrales concierne a las identidades colectivas y sus derechos. La tesis es que los marcos conceptuales son constitutivos de ciertas clases de entidades colectivas.

Salmerón se ocupó también de este problema en el artículo que hemos comentado. Recuerda la situación marginal y desventajosa de los grupos étnicos tradicionales dentro de naciones que a su vez han sido dependientes en el contexto internacional a diferentes niveles: económico, político y cultural. A lo largo de los últimos quinientos años, sin embargo, ha habido momentos en que la identidad de esos grupos se ha negociado en una relación de mestizaje cultural, principalmente con grupos de cultura europea (cf. Salmerón 1996, 82). La identidad de esos grupos «no es sólo su proyecto actual como elemento aislado, sino también nuestra mirada; de la misma manera que ésta sólo puede acercarse a aquella identidad en el proceso de comprensión de su proyecto y de su historia. Pero lo mismo puede decirse si invertimos el orden de las afirmaciones: su proyecto actual y su conciencia de pertenecer a una comunidad no es todo lo que define su identidad, hace falta también su diálogo con nosotros y la consideración de nuestros juicios» (Salmerón 1996, 82).

Es por medio de los marcos conceptuales y de las tradiciones que los grupos étnicos se ven a sí mismos como el grupo que son. Y lo mismo puede decirse de grupos de origen europeo. Cada grupo tiene sus propias tradiciones y sus recursos conceptuales según los cuales entienden su identidad. Esas tradiciones y esos recursos conceptuales establecen límites con respecto a las creencias que pueden tener los miembros de esos grupos. El papel de las creencias es crucial para la auto-comprensión de las personas y para la identidad de los grupos étnicos tradicionales.

Para nuestros propósitos aquí, entenderemos el concepto de creencia en el sentido propuesto por Luis Villoro en su libro Creer, Saber, Conocer (1982):

Un sujeto $\mathrm{S}$ cree que $p$ (donde $p$ se refiere al contenido de una proposición) si y sólo

si

1] S está en un estado disposicional adquirido $x$ para reaccionar de determinadas maneras bajo diferentes circunstancias.

2] $\mathrm{S}$ ha aprehendido $p$ (que es el objeto de la creencia).

3] $p$ determina $x$. 
Una creencia, pues, es un estado disposicional adquirido que causa un conjunto coherente de respuestas y que está determinado por un objeto o por una situación objetiva que ha sido aprehendida (Villoro 1982, 71).

Para comprender mejor por qué es importante traer a cuento una noción así de creencia, y el papel de las creencias y de los marcos conceptuales en la constitución de ciertos objetos sociales, examinemos un ejemplo propuesto en el artículo de Salmerón. Ahí él menciona como «hecho indudable que la política de reconocimiento de grupos sociales sólo puede hallar su verdadera dimensión en una sociedad plenamente democrática o que esté en camino de alcanzar tal plenitud» (Salmerón 1996, 74). Esto quiere decir que las sociedades democráticas son las mejor equipadas para aplicar la política del reconocimiento. Pero una sociedad en la que tal política fuera completamente aceptada y debidamente aplicada, sería una sociedad en la cual se aceptarían ciertas creencias específicas concernientes a los grupos sociales y a la existencia de sus derechos de grupo, con base en diferencias consideradas objetivas. De modo que la política del reconocimiento y su aplicación no sería independiente de las creencias y actitudes de los seres humanos dentro de esa sociedad democrática. Pero algunas de esas creencias serían sobre cuestiones de hecho, por ejemplo acerca de la naturaleza de las entidades colectivas y acerca de semejanzas y diferencias entre personas y entre grupos.

De acuerdo con la concepción de creencia de Villoro, si S cree que $p$, debe haber una situación objetiva aprehendida por $\mathrm{S}$, a saber, aquélla a la que se refiere $p$. Pero es claro que $\mathrm{S}$ puede estar en lo cierto, o puede estar equivocado con respecto a la naturaleza de $p$. La creencia implica la responsabilidad del sujeto de haber hecho un juicio, a saber, precisamente el juicio de que $p$ es aceptable (creíble). Por ejemplo, S puede creer que tiene agua frente a sí, cuando en realidad sólo hay un espejismo, en virtud de una peculiar manera en que los rayos de luz se reflejan en la carretera. En este caso $\mathrm{S}$ se equivocó en su juicio al aceptar la creencia $p$, de que había agua frente a ella. La mayor parte de las veces la gente no está consciente de que constantemente hace ese tipo de juicios. Pero podemos atribuir esta habilidad a cualquier sujeto racional capaz de discriminar entre creencias que le parecen aceptables y creencias que le parece que debe rechazar. De hecho éste es el meollo de lo que quiere decir ser racional. Para que sea posible que el sujeto aprehenda una cierta situación $p$ como el objeto de una creencia, y para que pueda hacer el juicio concomitante de aceptar o rechazar la creencia, el sujeto $\mathrm{S}$ requiere de un marco conceptual.

Un marco conceptual no es un mero conjunto de conceptos. También incluye reglas metodológicas para la aceptación y rechazo de creencias, así como creencias sustanciales, algunas de las cuales se encuentran firmemente 
atrincheradas, e incluye también normas y valores (epistémicos, morales y estéticos). Cuando se aprehende una situación objetiva, y se hace un juicio (aunque sólo sea de manera implícita e inconsciente) debe haber algún marco conceptual en operación.

En suma, la existencia de una creencia requiere: 1) de la aprehensión de una situación objetiva, y 2) de la operación de un marco conceptual que hace posible esa aprehensión y un juicio sobre la situación.

Así pues, la noción de marco conceptual se refiere a un conjunto de conceptos, reglas, normas, valores y fines, que se usa y se requiere para aprehender objetos o situaciones en el mundo, y para hacer juicios acerca de ellos. Por mi parte considero que esto es así con respecto a todos los objetos del mundo natural y social. Pero para los fines de nuestra discusión no tenemos que entrar en el más problemático caso de la aprehensión de hechos naturales y el papel de los marcos conceptuales en la existencia de objetos naturales. El problema que nosotros estamos discutiendo se refiere a la existencia y aprehensión de ciertos objetos y situaciones sociales, por ejemplo la identidad de entidades colectivas. La tesis es que los marcos conceptuales no sólo posibilitan la aprehensión de los individuos y colectividades como entidades con ciertas identidades específicas. La tesis es aún más fuerte: los marcos conceptuales son necesarios para la construcción de esas identidades.

Más aún, el tipo de situaciones en las cuales estamos interesados tienen que ver por ejemplo con la existencia de derechos. Pero la existencia de los mismos no es independiente de las creencias y actitudes de las personas en donde esos derechos supuestamente existen. La existencia de esos derechos depende de que sean reconocibles por los miembros de la sociedad en cuestión. Esto a su vez quiere decir que esos derechos existen si son aceptables racionalmente en esa sociedad. Ésta es una de las razones por las cuales quienes participan en las disputas sociales y políticas actuales están preocupados por convencer a la gente de que acepten la existencia de esos derechos. Pues si la gente cree en la existencia de los derechos, entonces tendrá la actitud disposicional de actuar reconociendo esos derechos, y esto es lo fundamental para afirmar que tales derechos existen. Si la mayoría de la gente no tiene la disposición para actuar reconociendo y respetando esos derechos, no podemos afirmar que los derechos realmente existen (aunque sería deseable que existieran y entonces hay que trabajar para hacerlos realidad).

Nótese que me estoy refiriendo a la aceptabilidad, por ejemplo, de ciertos derechos en el contexto de sociedades específicas. El derecho a la diferencia, si existe, sería un derecho que sostendríamos como válido en nuestra cultura y en nuestro contexto de interacción con miembros de otras culturas. 
El derecho a la diferencia del que estamos hablando es un derecho que puede ser reconocido dentro de las sociedades modernas, democráticas y plurales. Pero entonces debe ser un derecho reconocible desde la perspectiva de todos los marcos conceptuales que entren en juego en esa sociedad, incluyendo los de las comunidades tradicionales. La idea por supuesto es que el derecho pueda reconocerse después de las interacciones apropiadas entre agentes de los diversos grupos involucrados, y no se está proponiendo que el derecho en cuestión sea reconocido de hecho desde el principio por todos los participantes, como si su existencia fuera independiente de las creencias (disposiciones a actuar) de los participantes.

En resumen, he mencionado que hay dos condiciones que deben satisfacerse para que exista un hecho social: primero, debe haber una situación objetiva capaz de ser aprehendida por los miembros de la sociedad. Ésta será la situación que se requiere para que los miembros de la sociedad tengan creencias. Pero esa situación objetiva no es todavía el hecho social en cuestión, para ello se requiere la segunda condición, a saber, que los agentes pertinentes aprehendan esa situación social objetiva por medio de un marco conceptual, y que hagan un juicio con respecto a ella. Entonces es cuando la situación objetiva se convierte en un hecho social. Pero al hacer el juicio es que la gente puede equivocarse. Con respecto a las entidades como los grupos étnicos tradicionales -y como subrayaré después, como el Estado- el marco conceptual pertinente hace una contribución decisiva a su existencia y a su identidad. En tales casos, el marco conceptual constituye una condición necesaria, aunque no suficiente, para la existencia de la entidad relevante.

Pero los marcos conceptuales no surgen de manera espontánea. Los marcos conceptuales son entidades históricas, creadas y transformadas por los seres humanos. En gran medida los marcos conceptuales están conformados por conceptos. En el mundo occidental, los marcos conceptuales han sido producidos, preservados y transformados en buena medida por la obra de filósofos.

Un marco conceptual determinado puede ser discutido y re-elaborado en momentos particulares, y ésa es una tarea filosófica (aunque no necesariamente realizada por filósofos profesionales). Esto es lo que ocurre constantemente, por ejemplo, cuando se llevan a cabo debates sobre la soberanía, la existencia de derechos específicos, el alcance de los derechos, el rango de los beneficiarios, las obligaciones del Estado, etc., etc.

He sostenido que los marcos conceptuales son necesarios para la identidad de las culturas, y que en buena medida son el resultado del trabajo filosófico. Pero en el mundo social y político hay muchas entidades cuya existencia debe mucho también a las ideas filosóficas y tienen un carácter histórico, 
y por consiguiente en torno a ellas se da una liga indisoluble entre la filosofía y la historia de la filosofía. Ya he sugerido que el Estado es una de esas entidades. Para concluir este artículo, pasemos a examinar este problema mediante un análisis de una de las contribuciones de Luis Villoro al debate.

\section{El papel de las ideas filosóficas en la constitución de ciertos objetos sociales}

En virtud de los acontecimientos que se han suscitado en México en los últimos años, particularmente aquéllos relativos a los grupos indígenas, los cuales afectan directamente al Estado y su relación con dichos grupos, Luis Villoro ha insistido en que es necesario re-examinar la concepción del Estado. Aunque los problemas de ninguna manera son nuevos, dicho re-examen es urgente con el fin de proponer un nuevo modelo que sirva para orientar las acciones del propio Estado y de los mismos grupos étnicos y de sus representantes. Dicha transformación en la concepción del Estado es necesaria si se han de satisfacer las demandas de las culturas minoritarias en México (cf. Villoro 1995 y 1996).

Al sugerir formas en las que su argumento podría desarrollarse, Villoro llama la atención sobre el hecho de que el Estado Mexicano moderno tiene sus orígenes y se ha desenvuelto por medio de un proceso en el que ha habido una tensión esencial y constante entre la concepción liberal del Estado y una concepción social. La segunda debe entenderse en algunos aspectos semejante a las concepciones que actualmente han defendido los llamados comunitaristas.

La tesis que me interesa destacar es que las concepciones filosóficas de las que habla Villoro son constitutivas del Estado, y por tanto, para comprender al Estado Mexicano actual hay que entender esas concepciones que le subyacen y que lo apoyan. Es cierto que para comprender ciertos aspectos del Estado basta con un análisis de sus políticas actuales y de las ideas que las sustentan. Pero tal análisis sólo sería parcial. Si se quiere una visión y una comprensión más completa del Estado habrá que analizar también las concepciones que le dieron origen y que han contribuido a su identidad.

La filosofía moral y la filosofía política son importantes en una sociedad en la medida en la que tengan efectos sobre los problemas que emergen de la realidad social y política de esa sociedad. En relación con el Estado, los análisis morales y políticos deberían ser útiles para diseñar políticas que el mismo Estado podría llevar adelante, pero también deberían ser útiles para que el ciudadano común y corriente entienda lo que es el Estado, cuál es su papel, cuáles son sus propósitos, cuándo sus acciones son legítimas y sus políticas aceptables sobre bases morales. 
La razón por la cual es necesario entender el proceso histórico de desarrollo del Estado o de las culturas tradicionales para comprenderlos cabalmente es que se trata de sistemas dinámicos. Es preciso reconocer que es posible lograr una comprensión parcial de un sistema y de la manera en la que funciona, conociendo únicamente su estado presente. Pero un conocimiento más completo del sistema, y una comprensión de su funcionamiento, requiere que se conozcan los estados anteriores del sistema, así como de los rangos admisibles de variación de las variables que definen su identidad, sin que la misma se vea amenazada. También es preciso conocer las formas en las que el sistema ha reaccionado en el pasado frente a diferentes estímulos del exterior y ante diferentes cambios internos. Todo esto es necesario para hacer predicciones exitosas acerca de su comportamiento, y para diseñar políticas adecuadas si se quiere intervenir en su desarrollo, lo cual es el caso por ejemplo con respecto al Estado. Pero el conocimiento de estados anteriores y de tendencias es un conocimiento histórico.

Cuando se proponen soluciones a algunos de los problemas que plantea la situación de las minorías culturales, es muy probable que tales propuestas incluyan sugerencias de transformación de las instituciones vigentes y cambios de actitud hacia las culturas tradicionales, y quizá también cambios en esas mismas culturas. Las propuestas también probablemente sugerirán modificaciones en las concepciones y prácticas del Estado. Con el fin de hacer propuestas de ese estilo de manera responsable, es necesario tener una comprensión del Estado lo más completa posible, lo mismo que con respecto a las culturas involucradas. Ésta es una razón más por la cual es necesario tener un conocimiento lo más completo posible del Estado y de las culturas tradicionales, y para ello hemos sostenido que se requiere comprender las concepciones que han contribuido a formar su identidad.

Podría objetarse que me estoy refiriendo a un tipo de entidades sociales y a una clase de conocimiento de ellas cuya producción es tarea de las ciencias sociales empíricas, incluyendo dentro de ellas a la historia como disciplina intelectual. Pero ésta no es materia de estudio de la filosofía, y no es razonable esperar que la filosofía ofrezca u obtenga ese tipo de conocimiento -continuaría la objeción.

La respuesta a dicha objeción sería que es verdad que no debe esperarse que la filosofía ofrezca un conocimiento cabal de esas entidades. Sin embargo, en la medida en la que algunas ideas filosóficas son constitutivas de esas mismas entidades, se requiere el análisis y la evaluación de esas ideas, y ésta es una tarea filosófica. Por consiguiente, la filosofía necesariamente desempeña un papel importante en la producción de conocimiento de tales entidades. Pero es claro que no debemos esperar que la filosofía diga todo lo que hay que decir y explicar con respecto a ellas. 
Las instituciones de las que hemos hablado son entidades históricas creadas, sostenidas y transformadas por medio de creencias, prácticas y actitudes de la gente. Algunas instituciones pueden ser relevantes para las principales tendencias en el desarrollo histórico de un país, mientras que otras pueden no serlo, pero todas ellas serán históricas. Las concepciones filosóficas que subyacen al Estado son pues tanto filosóficas como históricas. Por lo general, los fundamentos filosóficos de las instituciones y tal vez de culturas enteras han requerido de un proceso de sedimentación, semejante al proceso de desarrollo de las instituciones mismas. Así, las ideas filosóficas que contribuyen a la constitución del Estado son parte de la historia «tout court», tanto como lo son de la historia de las ideas. Pero como se trata al mismo tiempo de ideas filosóficas, también forman parte de la historia de la filosofía.

Es esta relación indisoluble entre concepciones filosóficas e instituciones lo que hace históricas a dichas concepciones, y es lo que hace necesaria una perspectiva histórica para la discusión filosófica de algunas cuestiones morales y políticas que emergen de la multiculturalidad. Esto significa que cualquiera que se comprometa con la actividad intelectual de analizar el Estado tiene que comprometerse también con un análisis filosófico tanto como con uno histórico-filosófico.

\section{La comunidad filosófica y la división intelectual del trabajo filosófico}

He sostenido que la historia de la filosofía es pertinente para la filosofía moral y política, al menos en tres sentidos:

1) Porque una perspectiva y un conocimiento históricos son útiles, aunque no necesarios, para conformar ideas que son pertinentes para comprender problemas y proponer soluciones y guías para la acción en relación con problemas morales y políticos.

2) Porque muchos análisis filosóficos están conceptualmente conectados a una tradición, y una tradición es tanto un objeto histórico como una herramienta conceptual, la cual puede operar en la comprensión de los problemas y como trasfondo para ofrecer soluciones.

3) Porque los análisis históricos de ideas filosóficas son necesarios para comprender el fundamento de instituciones y de culturas. La identidad de algunas instituciones como el Estado, y de muchas culturas, depende en parte de ideas filosóficas. Por consiguiente, para poder comprender correctamente a esas instituciones, es necesario comprender las ideas que contribuyeron a definir su identidad tal y como fueron discutidas en su origen y como se desarrollaron en la historia. Esta comprensión es a su vez necesaria si se proponen cambios en las 
instituciones o en los rasgos fundamentales de las culturas. Pero esa comprensión es histórica y filosófica a la vez.

Ahora bien, habiendo sostenido lo anterior, quisiera concluir declarando que la tesis aquí defendida no implica que sea necesario que un solo individuo deba desarrollar tanto ideas filosóficas como estudios histórico-filosóficos para hacer importantes contribuciones a la filosofía.

Quisiera subrayar más bien que el desarrollo de la filosofía, como el de cualquier otra disciplina, es una tarea de una comunidad. La historia de la filosofía es necesaria para tratar de manera adecuada los problemas que emergen de la multiculturalidad. Pero la tarea de enfrentar esos problemas es colectiva. Más aún, la tarea de elaborar el instrumental conceptual adecuado para pensar en esos problemas y para proponer soluciones, en tanto es filosófica, es tarea de la comunidad filosófica.

Dentro de la comunidad filosófica, de manera espontánea u organizada, hay una división del trabajo. Así, la tesis que he defendido no implica que cada contribución individual a los problemas de la multiculturalidad deba incluir análisis históricos. Lo que implica es que si la comunidad filosófica ha de hacer contribuciones importantes para la comprensión de esos problemas, y más aún, si ha de hacer propuestas que afecten al Estado, a las culturas tradicionales y a sus relaciones, entonces debe producir análisis histórico-filosóficos en los cuales se analicen las tradiciones filosóficas y se examine su operación, y en donde se hagan explícitas y se critiquen las ideas que han constituido a las instituciones relevantes.

La comunidad filosófica puede estar organizada de manera tal que algunos de sus miembros se concentren en la discusión histórica estricta -en contextos del pasado-, algunos otros de sus miembros sobre ideas del pasado de una manera pertinente para los problemas actuales, otros más sobre discusiones puramente conceptuales dentro del contexto contemporáneo, y todavía otros que apliquen las ideas a problemas y a situaciones concretos. Lo que es importante es que la comunidad garantice que se cubra todo ese espectro. La situación óptima es aquélla en donde los diferentes miembros de la comunidad, y los diversos grupos que se especializan en cada uno de esos aspectos, establecen una estrecha comunicación, intercambian ideas, se critican constructivamente y desarrollan controversias enriquecedoras, pues todo eso ayuda a construir teorías más profundas. Algunos individuos querrán concentrarse y especializarse en algunos campos dentro del amplio espectro. Otros, quizá con más talento, desearán y serán capaces de abarcar varios, o todos, los campos. Éste ha sido el caso de los tres filósofos cuyo trabajo hemos comentado. Eso explica en buena parte su liderazgo dentro de la comunidad filosófica latinoamericana. 


\section{REFERENCIAS}

Cabrera, Isabel 1996, «Actitud y valores. En torno a la concepción moral de Fernando Salmerón», en L. Olivé y L. Villoro (eds.) 1996, pp. 245-251.

Garzón Valdés, Ernesto 1993, Derecho, Ética y Política, Centro de Estudios Constitucionales, Madrid.

Garzón Valdés, Ernesto 1993a, «El problema ético de las minorías étnicas», en L. Olivé (ed.) Ética y Diversidad Cultural, Fondo de Cultura Económica-UNAM, México, pp. 31-57.

Garzón Valdés, Ernesto 1993b, «La antinomia entre las culturas», en Garzón Valdés y Salmerón (eds.), Epistemología y Cultura, en torno a la obra de Luis Villoro, UNAM, México, 219-242.

Garzón Valdés, Ernesto 1996, «Algunas confusiones acerca de los problemas morales de la diversidad cultural», en Villoro y Olivé (eds.) 1996, pp. 81-109.

Gracia, Jorge, Philosophy and Its History, Issues in Philosophical Historiography, State University of New York Press, Albany N.Y., 1992.

Gutmann, Amy 1994 (editora), Multiculturalism, Examining the Politics of Recognition, Princeton University Press, Princeton, N. J.

Kymlicka, Will 1989, Liberalism, Community, and Culture, Oxford University Press.

Kymlicka, Will (ed.) 1995, The Rights of Minority Cultures, Oxford University Press.

Laudan, Larry 1996, Beyond Positivism and Relativism, Westview Press, Boulder, Colorado.

Salmerón, Fernando 1971, La Filosofia y las Actitudes Morales, Siglo XXI Editores, México.

Salmerón, Fernando 1988, «Moralidad y racionalidad», en L. Olivé (ed.), Racionalidad, Siglo XXI (ed.), México, 1988, pp. 19-45.

Salmerón, Fernando 1991, Enseñanza y Filosofía, Fondo de Cultura Económica.

Salmerón, Fernando 1996, «Ética y diversidad cultural», en Cuestiones Morales, Osvaldo Guariglia (ed.), volumen 12 de la ENCICLOPEDIA IBEROAMERICANA DE FILOSOFÍA, Ed. Trotta-CSIC, Madrid, 1996, pp. 67-85.

Salmerón, Fernando 1998, Diversidad Cultural y Tolerancia, Paidós-UNAM, México.

Salmerón F. y L. Olivé (eds.) 1994, La Identidad Personal y la Colectiva, UNAM, México. Taylor, Charles 1994, «The politics of recognition», en Gutmann 1994.

Villoro, Luis 1982, Creer, Saber, Conocer, Siglo XXI Editores, México.

Villoro, Luis 1985, «Autenticidad en la cultura», en El Concepto de Ideología y otros ensayos, Fondo de Cultura Económica, México, 1985, pp. 171-196.

Villoro, Luis 1993, «Aproximaciones a una ética de la cultura», en León Olivé (ed.), Ética y Diversidad Cultural, Fondo de Cultura Económica-UNAM, México, pp. 131-154.

Villoro, Luis 1994, «Sobre la identidad de los pueblos», en Salmerón y Olivé (eds.) 1994, pp. 85-100. 
Villoro, Luis 1995, «¿Crisis del Estado-nación mexicano?», Dialéctica (México), Nueva época, Año 18, núm. 27, 1995, pp. 14-23.

Villoro, Luis 1996, «Igualdad y diferencia: un dilema político», en Villoro y Olivé (eds.), 1996, pp. 111-122.

Villoro, Luis 1998, Estado Plural, Pluralidad de Culturas, Paidós-UNAM, México.

Villoro, Luis y Olivé León (eds.) 1996, Filosofia Moral, Educación e Historia. Homenaje a Fernando Salmerón, UNAM, México, 1996. 